\title{
Magnitude of late initiation of antenatal care and its associated factors among pregnant women attending antenatal care in Woldia Public Health Institution, North Wollo, Ethiopia.
}

Ashete Adere ( $\square$ ashelove039@gmail.com )

Woldia University https://orcid.org/0000-0001-5542-2786

Sewnet Tilahun

Bule Hora University

Research article

Keywords: Antenatal care, Pregnancy, Late initiation, Woldia Town

Posted Date: September 1st, 2020

DOI: https://doi.org/10.21203/rs.3.rs-61704/v1

License: (a) (i) This work is licensed under a Creative Commons Attribution 4.0 International License. Read Full License 


\section{Abstract}

Background: The World Health Organization states that every pregnant woman is at risk of complications. Antenatal care is vital to reduce complications and more likely to be effective if women begin receiving care in the first trimester of pregnancy and continue to receive care throughout pregnancy. The maternal mortality ratio in Ethiopia was estimated at 412 deaths per 100,000 live births in 2016.

Methods: Institutional based cross-sectional study design was used. Data collection was collected using an interviewer-administered questionnaire. A systematic sampling technique with proportional allocation was used to get the final 390 study participants. Data was entered, cleared, and analyzed with Statistical Package for Social Sciences Version (SPSS) 20. Descriptive measures were presented with frequencies, tables, and diagrams. A binary logistic regression model was used to identify predictors of late antenatal care initiation.

Results: The prevalence of late antenatal care initiation was 59.5\% with $95 \% \mathrm{Cl}$ [54.6-64.1]. Residence of the mother [AOR $=5 ; 95 \% \mathrm{Cl}:(1.423,17.86)$, Paying for health services [AOR $=13.9 ; 95 \% \mathrm{Cl} 3.531,54.86]$, Planed for pregnancy [AOR $=13.4 ; 95 \% \mathrm{Cl}: 4.018,44.487]$, Counseled for ANC [AOR = 13.6; 95\% Cl:6.090, 63.127] and number of lifetime pregnancies (gravidity) [AOR $=5.5 ; 95 \% \mathrm{Cl}: 2.077,14.36]$ were factors significantly associated with late initiation of ANC.

Conclusion: More than $50 \%$ of women attended antenatal care follow-up late from the recommended time of initiation. Residence, payment for pregnancy-related health services, plan for pregnancy, counseling, and advice regarding antenatal care follow-up and gravidity were factors significantly associated with late antenatal care initiation.

\section{Background}

The antenatal care (ANC) provision or regular check-ups during pregnancy through the public health services in modern obstetrics was started during the late 1930s in the United Kingdom and Northern Ireland [1]. ANC is important for the survival and wellbeing of both the mother and the infant. Skilled care during pregnancy is an important intervention in reducing maternal and neonatal morbidity and mortality [2].

World Health Organization (WHO) recommends a minimum of eight contacts: five contacts in the third trimester, one contact in the first trimester, and two contacts in the second trimester, While many African countries are still struggling to achieve high coverage of four antenatal visits [3].

Antenatal care is more likely to be effective if women begin receiving care in the first trimester of pregnancy and continue to receive care throughout pregnancy, according to accepted standards of periodicity [4]. The universal recommendation for the first ANC initiation is in the first trimester. According to WHO the first trimester is the best time for a mother to book her pregnancy [5].

WHO ANC model states that every pregnant woman is at risk of complications and recommends early ANC visits. The visit is used to segregate pregnant women into two groups based on the previous history of pregnancy, current pregnancy state, and general medical conditions. Those eligible to receive routine ANC 
(basic component) and those who need special care based on their specific health conditions or risk factors on average account for $25 \%$ of all pregnant women initiating ANC [6].

Worldwide there's an enormous discrepancy within the prevalence lately ANC follow up among pregnant mothers, starting from 27.5 to $88 \%$ in developed and developing countries respectively [7]. In Latin America, the Caribbean, the Middle East, and North Africa, two-thirds of women present for antenatal care visit in the first trimester, while in sub-Saharan Africa, where women presenting for antenatal care are most likely to wait until the second trimester and a relatively substantial proportion present only in the third trimester. Although women in sub-Saharan Africa make their first antenatal visit rather late in pregnancy, they nonetheless tend to report more than one visit [8].

The South African National Department of Health recommended that women should visit the ANC clinic as soon as they realize that they are pregnant and definitely before 20 weeks of gestation. The ANC services should start with women's first visit irrespective of gestational age. Antenatal Care guidelines recommend that pregnant women should start their ANC visit at 12 weeks of gestation. Despite the provision of free ANC services, South Africa is still performing poorly compared to other middle-income countries [9].

In Ethiopia, only $20 \%$ of women had their first ANC during the first trimester, $26 \%$ during their fourth to the fifth month of pregnancy, and $14 \%$ during their sixth to the seventh month of pregnancy. Two percent of women did not receive any ANC until the eight months of pregnancy or later [2].

Poor and inadequate quality of care was a strong predictor for late ANC initiation, community-based information, health education and communication on ANC services, socio-economic and individual perception and knowledge of ANC services are major contributors to start ANC visit late in time [10].

Maternal knowledge on early ANC visit, planned pregnancy and parity were factors associated with early ANC visit, mothers of age, media access, advise to initiate ANC during the recommended time after amenorrhea, residence, husband's occupation, [11-14].

The maternal mortality ratio in Ethiopia was estimated at 412 deaths per 100,000 live births in 2016 (17). These maternal deaths could have been prevented if the pregnant women or adolescent girls had been able to access quality antenatal care (ANC) (it includes early initiation of antenatal care). Sixty percent of the stillbirths (1.46 million) occurred during the antepartum period and mainly due to untreated maternal infection, hypertension, and poor fetal growth [6].

Pregnant women should be offered infection early in ANC since appropriate ANC interventions can reduce mother-to-child transmission of HIV infection due to offered screening for HIV at ANC. Screening for syphilis should be offered to all pregnant women at an early stage. In pregnant women with untreated syphilis, 70$100 \%$ of infants will be infected and one third will be stillborn [6]. Pregnant women also offered iron and folic acid supplementation in early pregnancy for those who are at risk of nutritional deficiency until 12 weeks of gestation reduces the risk of a baby born with neural tube defects such as anencephaly and spinal bifida [15]. 
Despite ANC is provided free of charge and there is increased accessibility; low utilization and late booking is still a major problem [16, 17]. According to the Ethiopian Demographic Health Survey 2016 (EDHS), only $20 \%$ of mothers start ANC early as per the recommendation [18].

Even though there is good health service coverage in Ethiopia, women come late for ANC follow up. Besides, there is a scarce study on magnitude and associated factors for late ANC among women attending ANC at Woldia town public health institutions, Northern Ethiopia. Therefore, this study aimed to assess the magnitude and factors associated with late initiation of ANC visit at Woldia public health institutions.

\section{Methods}

\section{Study area and period}

The study was conducted at Woldia public health institutions. Woldia town is the capital city of North Wollo Zone. It is located $520 \mathrm{Km}$ away from the capital city Addis Ababa and $360 \mathrm{Km}$ from the Regional capital city Bahir Dar. Based on the 2007 national census conducted by the Central Statistical Agency of Ethiopia (CSA), it has a total population of 46,139, of whom 23,000 are men and 23,139 women. Currently, Woldia town has one governmental general hospital and two health centers (Woldia Health center (HC) and Gonder berr HC). The study was conducted from May 01 to June 01, 2019.

\section{Study design}

A facility-based cross-sectional study was conducted.

\section{Source and study population}

The source population was all pregnant women attending antenatal care visits at Woldia town public health institutions. Whereas the study population was sampled pregnant women attending ANC at Woldia town Public Health institutions.

\section{Sample size and sampling procedure}

\section{Sample size}

The final sample of the study was determined with the assumptions of a $95 \%$ confidence level, $5 \%$ margin of error. The sample size was calculated for the prevalence and the factors and the sample size calculated for the prevalence yields the largest and selected.

Using the formula

$$
n=\left(\mathrm{z} \frac{\alpha}{2}\right)^{2} p(1-P) / d^{2}
$$

Where $\mathrm{n}=$ the desired sample size

$Z=$ level of significance at $95 \%$ confidence interval 
$\mathrm{P}=$ is the prevalence of late ANC visit (taken from a study conducted at public health centers of Debre Markos $=59.4 \%$

$q=1-p$

$d=$ margin of error

Accordingly;

$n=(1.96)^{2} 0.594(1-0.594) /(0.05)^{2}=378$

By adding $3 \%$ non-response rate $378+12=390$

\section{Sampling procedure}

First, the sampled number of pregnant mothers required for this study $=390$ allocated proportionally at each of the three public health institutions based on the number of antenatal care services delivered From January 01 to April 30 (fig.1).

Inclusion and Exclusion Criteria

\section{Inclusion criteria}

Pregnant mothers attending antenatal care visits at the time of data collection were included.

\section{Exclusion criteria}

Mothers who do not respond due to severe medical or mental illness were excluded

\section{Study variables}

\section{Dependent variables}

Late initiation of ANC

\section{Independent variables}

\section{Socio-demographic factors}

Women's age, residence, income, women's educational status, marital status, husband's educational status, occupation of the mother, occupation of the husband.

\section{Obstetrics factors}

Parity, gravidity, previous history of ANC, unplanned pregnancy

\section{Partner related factors}




\section{Data collection tools and techniques}

Data were collected using an interviewer-administered questionnaire. The questionnaire was adopted by reviewing the literature. The questionnaire was first prepared in English and then translated to the local language Amharic. The data collection was conducted by trained Midwives.

\section{Data Quality control}

A pretest was done by taking $5 \%$ of the sample from the Kobo Hospital, one week before data collection to check whether the questionnaire was correct and consistent. Data was cleared and checked for completeness and consistency by the principal investigators. The training was given for data collectors regarding the purpose of the research and issues associated with the questionnaire including the method and steps of data collection, the contents of the questionnaire, proper coding of the response variables.

\section{Data Processing and analysis}

Data was entered into EPI info version 3.5.1 for data exploration and cleaning. The cleaned data was exported to SPSS version 25 for statistical analysis. Descriptive statistics were used to summarize categorical variables. Both bivariate and multivariable analyses were performed using logistic regression and adjusted odds ratios (AOR) with $95 \%$ confidence intervals for factors associated with late initiation of antenatal care. P-value $<0.05$ was considered statistically significant.

\section{Results}

\section{Sociodemographic characteristics of participants}

The mean age of the mother was 28 years ( $S D \pm 5.4$ ). More than half of the respondents $213(54.6 \%)$ were residents of urban areas. Of the total mothers, 228(58.5\%) were Orthodox Christians. The majority of the mothers were $357(91.5 \%)$ Amhara ethnic group. Of the total 390 mothers, $339(86.9 \%)$ were married mothers (Table 1). 
Table 1

Sociodemographic characteristics of mothers attending ANC at Woldia town public health institutions, 2019.

\begin{tabular}{|c|c|c|c|c|}
\hline S.N & Socio-demographic Characteristics & Category & Frequency & Percent \\
\hline \multirow[t]{3}{*}{1} & \multirow[t]{3}{*}{ Age } & $18-24$ & 102 & 26.1 \\
\hline & & $25-34$ & 232 & 59.5 \\
\hline & & $>=35$ & 56 & 14.3 \\
\hline \multirow[t]{2}{*}{2} & \multirow[t]{2}{*}{ Residence } & Urban & 213 & 54.6 \\
\hline & & Rural & 177 & 45.4 \\
\hline \multirow[t]{4}{*}{3} & \multirow[t]{4}{*}{ Religion } & Orthodox & 228 & 58.5 \\
\hline & & Muslim & 132 & 33.8 \\
\hline & & Protestant & 25 & 6.4 \\
\hline & & Catholic & 5 & 1.3 \\
\hline \multirow[t]{3}{*}{4} & \multirow[t]{3}{*}{ Ethnicity } & Amhara & 357 & 91.5 \\
\hline & & Tigrie & 28 & 7.2 \\
\hline & & Others & 5 & 1.3 \\
\hline \multirow[t]{4}{*}{5} & \multirow[t]{4}{*}{ Marital status } & Single & 23 & 5.9 \\
\hline & & Married & 339 & 86.9 \\
\hline & & Widowed & 18 & 4.6 \\
\hline & & Divorced & 10 & 2.6 \\
\hline \multirow[t]{5}{*}{6} & Maternal & Read and write only & 92 & 23.6 \\
\hline & \multirow[t]{4}{*}{ Educational status } & Cannot read and write & 103 & 26.4 \\
\hline & & Primary & 63 & 16.2 \\
\hline & & Secondary & 70 & 17.9 \\
\hline & & Collage and above & 62 & 15.9 \\
\hline \multirow[t]{5}{*}{7} & Husband & Cannot read and write & 57 & 16.8 \\
\hline & \multirow[t]{4}{*}{ educational status } & Read and write only & 66 & 19.5 \\
\hline & & Primary & 31 & 9.1 \\
\hline & & Secondary & 90 & 26.5 \\
\hline & & Collage and above & 95 & 28.0 \\
\hline 8 & Maternal & Government & 85 & 21.8 \\
\hline
\end{tabular}




\begin{tabular}{|c|c|c|c|c|}
\hline S.N & Socio-demographic Characteristics & Category & Frequency & Percent \\
\hline & Occupation & Private & 30 & 7.7 \\
\hline & & Daily laborer & 11 & 2.8 \\
\hline & & Housewife & 222 & 56.9 \\
\hline & & Merchant & 30 & 7.7 \\
\hline & & Others & 12 & 3.1 \\
\hline \multirow[t]{5}{*}{9} & Husband & Government & 121 & 35.7 \\
\hline & Occupations & Private & 71 & 20.9 \\
\hline & & Daily laborer & 49 & 14.5 \\
\hline & & Merchant & 90 & 26.5 \\
\hline & & Others & 8 & 2.4 \\
\hline \multirow[t]{3}{*}{10} & Family income & $\leq 2000$ birr & 62 & 15.9 \\
\hline & & $2,001-4,000$ birr & 172 & 44.1 \\
\hline & & $>4,000$ birr & 156 & 40 \\
\hline \multirow[t]{4}{*}{11} & Distance & $<30$ minutes & 105 & 26.9 \\
\hline & from health facility & $30-59$ minutes & 170 & 43.6 \\
\hline & & $1-3$ hours & 80 & 20.5 \\
\hline & & $>3$ hours & 35 & 9.0 \\
\hline
\end{tabular}

\section{Obstetric factors}

Of the total respondents, 295(75.6) were multigravida. The majority of the respondents 230 (60.0\%) had less than two alive children, $175(44.9 \%)$ had a history of ANC before the current pregnancy. Nearly a quarter of the respondents 108 (27.7\%) did not have a plan for the current pregnancy (Table2). 
Table 2

Obstetric factors of mothers attending ANC at Woldia town public health institutions, 2019.

\begin{tabular}{|c|c|c|c|c|}
\hline \\
\hline S.N & Obstetrics factors & Variable & Frequency & Percent \\
\hline \multirow[t]{2}{*}{01} & \multirow[t]{2}{*}{ Gravidity } & Primigravida & 95 & 24.4 \\
\hline & & Multigravida & 295 & 75.6 \\
\hline \multirow[t]{2}{*}{02} & \multirow[t]{2}{*}{ Parity } & Primipara & 180 & 46.2 \\
\hline & & Multipara & 210 & 53.8 \\
\hline \multirow[t]{3}{*}{03} & \multirow[t]{3}{*}{ Number of alive children } & $0-2$ & 230 & 60.0 \\
\hline & & 3 to 5 & 139 & 35.6 \\
\hline & & $>5$ & 21 & 5.4 \\
\hline \multirow[t]{2}{*}{04} & \multirow[t]{2}{*}{ Previous ANC } & Yes & 175 & 44.9 \\
\hline & & No & 215 & 55.1 \\
\hline \multirow[t]{2}{*}{05} & \multirow[t]{2}{*}{ Payment for health service } & Yes & 52 & 13.3 \\
\hline & & No & 338 & 86.7 \\
\hline \multirow[t]{2}{*}{07} & \multirow[t]{2}{*}{ Is pregnancy planned? } & Yes & 282 & 72.3 \\
\hline & & No & 108 & 27.7 \\
\hline \multirow[t]{2}{*}{09} & \multirow[t]{2}{*}{ Counseled for ANC follow-up } & Yes & 247 & 63.3 \\
\hline & & No & 143 & 36.7 \\
\hline \multirow[t]{4}{*}{10} & \multirow[t]{4}{*}{ Counseled by } & HEWs & 109 & 44.1 \\
\hline & & Media & 44 & 17.8 \\
\hline & & Family & 52 & 21.1 \\
\hline & & Others & 42 & 17.0 \\
\hline \multirow[t]{2}{*}{11} & \multirow[t]{2}{*}{ ANC for current pregnancy } & Before 12 weeks & 158 & 40.5 \\
\hline & & After 12 weeks & 232 & 59.5 \\
\hline
\end{tabular}

\section{Partner related characteristics}

From the total respondents, nearly a quarter of 95(24.4) of their husbands had no plan for the current pregnancy. Around 226 (57.9\%) of husbands of respondents did not know when to start ANC follow up by their wives. One hundred and fifty-eight (40.5\%) of the respondents had come for ANC with their husbands (Table 3). 
Table 3

Partner related characteristics of mothers attending ANC at Woldia town public health institutions, 2019.

\begin{tabular}{|c|c|c|c|c|}
\hline S.N & Variable & Responses & Frequency & Percent \\
\hline \multirow[t]{2}{*}{1} & \multirow[t]{2}{*}{ Pregnancy planned by husband } & Yes & 295 & 75.6 \\
\hline & & No & 95 & 24.4 \\
\hline \multirow[t]{2}{*}{2} & Your husband knows when to & Yes & 164 & 42.1 \\
\hline & start ANC & No & 226 & 57.9 \\
\hline \multirow[t]{2}{*}{3} & \multirow[t]{2}{*}{ If, yes when to start } & Before 12 weeks & 68 & 41.5 \\
\hline & & After 12 weeks & 96 & 58.5 \\
\hline \multirow[t]{2}{*}{4} & Your husband come with you & Yes & 158 & 40.5 \\
\hline & for ANC & No & 232 & 59.5 \\
\hline
\end{tabular}

Factors associated with the time of ANC initiation

Mothers who reside in urban areas were five times more likely to initiate ANC early than rural residents.

Payment for health services, Plan for pregnancy, Counseled for ANC, and the number of lifetime pregnancies was factors significantly associated with late initiation of ANC(Table 4). 
Table 4

Factors associated with late initiation of ANC among mothers attending ANC at Woldia town public health institutions, 2019.

\begin{tabular}{|c|c|c|c|c|c|}
\hline No & Questions & Responses & Remark & & \\
\hline \multirow[t]{2}{*}{ Factors } & & \multicolumn{2}{|c|}{ Late ANC Initiation } & \multirow[t]{2}{*}{$\operatorname{coR}(95 \% \mathrm{Cl})$} & \multirow[t]{2}{*}{ AOR(95\%Cl) } \\
\hline & & No & Yes & & \\
\hline \multirow{2}{*}{$\begin{array}{l}\text { Residence of } \\
\text { the mother }\end{array}$} & Urban & 103 & 110 & $2.077(1.369,3.150)$ & $5.042(1.423,17.86) *$ \\
\hline & Rural & 55 & 122 & 1 & 1 \\
\hline \multirow[t]{2}{*}{ History of ANC } & Yes & 89 & 87 & $2.150(1.424,3.245)$ & $A$ \\
\hline & No & 69 & 145 & 1 & 1 \\
\hline \multirow{2}{*}{$\begin{array}{l}\text { History of } \\
\text { payment for } \\
\text { health services }\end{array}$} & Yes & 41 & 11 & $7.040(3.488,14.209)$ & $13.9(3.53,54.86)^{\star *}$ \\
\hline & No & 117 & 221 & 1 & 1 \\
\hline \multirow{2}{*}{$\begin{array}{l}\text { Is pregnancy } \\
\text { planned? }\end{array}$} & Yes & 139 & 143 & $4.553(2.633,7.873)$ & $13.4(4.02,44.49)^{\star \star}$ \\
\hline & No & 19 & 89 & 1 & 1 \\
\hline \multirow{2}{*}{$\begin{array}{l}\text { Counseled for } \\
\text { ANC follow up }\end{array}$} & Yes & 127 & 120 & $3.824(2.391,6.115)$ & $13.6(6.09,63.13)^{\star \star}$ \\
\hline & No & 31 & 112 & 1 & 1 \\
\hline \multirow{2}{*}{$\begin{array}{l}\text { Do your } \\
\text { husband come } \\
\text { for ANC for } \\
\text { current } \\
\text { pregnancy }\end{array}$} & Yes & 80 & 78 & $0.494(0.325,0.747)$ & A \\
\hline & No & 78 & 154 & 1 & 1 \\
\hline \multirow[t]{2}{*}{ Gravidity } & Primgravida & 47 & 48 & $1.62(1.02,2.58)$ & $5.461(2.07,14.36)^{*}$ \\
\hline & Multigravida & 111 & 184 & 1 & 1 \\
\hline \multirow[t]{2}{*}{ Parity } & Multipara & 65 & 115 & $0.711(0.473,1.070)$ & $A$ \\
\hline & Primipara & 93 & 117 & 1 & \\
\hline
\end{tabular}

COR: crude odds ratio. AOR: adjusted odds ratio.Cl: Confidence Interval.*statistically significant variables at $p<0.05 .{ }^{*}$ Statistically significant variables at $p<0.001 .{ }^{a}$ Not significant in stepwise backward logistic regression.

\section{Discussion}

The findings of this study revealed that the prevalence of late antenatal care initiation among study subjects was $59.5 \%$. This finding was greater than a study conducted in Colombia (29.7\%)[14], which might be attributable to demographic and cultural differences. The finding was less than a study conducted at Debrebirhan health institutions (73.8\%) [17], Gonder town (64.9\%) [22], and study conducted at Southern Ethiopia (79.8\%) [21]. this might be attributable to the difference in the time of the study. 
In this study, mothers from the urban residence were nearly five times more likely to initiate ANC at and before 12 weeks of gestation. This finding is in line with a study conducted in Zambia, EDHS 2016 [19, 24], this is because of the differences in the awareness level and access to health services among rural and urban mothers.

Mothers who had a history of payment-related health services were nearly 14 times more likely to initiate ANC late than those who had not paid, attributable to those who had paid previously for health services might fear the fee and come late for antenatal care. This finding also revealed that those mothers who had planned for the current pregnancy were 13 times more likely to initiate ANC before /at 12 weeks of gestation than those mothers who had no plan. This finding was in line with the study conducted at Debrebirhan health institutions [17], Southern Ethiopia, Addis Abeba [21, 23] It is because of mothers who did not have a plan for their pregnancies, might know their pregnancy status late, or do not want to disclose their pregnancy status.

According to this study mothers who had counseled and advised regarding ANC were 13.5 more likely to initiate ANC before/at 12 weeks of gestation than those mothers who did not. The finding is in line with a study conducted at Addis Abeba [23]. This is because of mothers who were advised on antenatal care follow-up understood the significance of initiating antenatal care follow up early.

The findings of this study also show that primigravida mothers were 5.5 times more likely to initiate ANC before/at 12 weeks of gestation than multigravida mothers. The finding was similar to the study conducted at Tanzania [20] and Southern Ethiopia [21]. This might be due to mothers who did not have previous exposure for pregnancy fear the risks and seek immediate health care.

\section{Conclusion}

Our study showed that $59.5 \%$ of mothers attended antenatal care follow-up late from the recommended time of initiation. Residence, payment for pregnancy-related health services, plan for pregnancy, Counseled, and advised regarding antenatal care follow-up and gravidity were factors significantly associated with antenatal care initiation.

\section{Abbreviations}

AOR Adjusted Odd Ratio

ANC Antenatal Care

COR Crude Odd Ratio

EDHS Ethiopian Demographic Health Survey

HC Health Center

SPSS Statistical Package for Social Sciences

Page 12/16 


\section{Declarations}

\section{Ethics approval and consent to participate}

Ethical clearance was obtained from Woldia University, an Ethical review committee. Written informed consent was obtained from study participants. Written consent was obtained before data collection and confidentiality of the information was maintained throughout the study by excluding names as identification in the study.

\section{Consent for publication}

Not applicable

\section{Availability of data and materials}

The original data for this study are available from the corresponding author on reasonable request.

\section{Competing Interest}

The authors declare that there are no conflicts of interest regarding the publication of this paper.

\section{Funding}

No funding available for this study.

\section{Authors' Contributions}

AA conceived the research idea, designed the study, collected data, analyzed it, interpreted the result, and prepared the manuscript for publication. ST collected data, reviewed the draft of the manuscript, and checked for grammatical and spelling errors. All authors have read and approved the manuscript before sending it for the publication.

\section{Acknowledgments}

The authors would like to express their appreciation to Woldia General Hospital, Gonder berr HC, and Woldia $\mathrm{HC}$ for their unreserved support during the data collection process. 


\section{References}

1. World Health Organization. Trends in maternal mortality: 1990 to 2015: Estimates by WHO, UNICEF, UNFPA, The World Bank, and the United Nations Population Division: Executive summaryreproductivehealth/publications/monitoring/maternal-mortality-/en/. 2015.

2. Central Statistical Agency [Ethiopia]. Ethiopia Demographic and Health Survey Addis Ababa, Ethiopia and Calverton, Maryland, USA: Central statistical agency and ICF international. 2016.

3. WHO antenatal care randomized trial: a manual for the implementation of the new model. Accessed May 14. 2019. https://apps.who.int/iris/handle/10665/42513.

4. Villar J, Ba'aqeel H, Piaggio G, et al. WHO antenatal care randomized trial for the evaluation of a new model of routine antenatal care [published correction appears in Lancet 2001 Nov 3;358(9292):1556]. Lancet. 2001;357(9268):1551-64. DOI:10.1016/s0140-6736(00)04722-x.

5. WHO antenatal care randomized trial: a manual for the implementation of the new model. Accessed May 14. 2019. https://apps.who.int/iris/handle/10665/42513.

6. Le Nguyen TT, Deoisres W. Factors predicting timely initiation of antenatal care among pregnant women in Binh Dinh Province, Vietnam. J Nurs Sci Health. 2016;38(4):123-36.

7. WHO | Antenatal care in developing countries. Promises, achievements, and missed opportunities: an analysis of trends, levels, and differentials. WHO. Accessed May 14. 2019.http://www.who.int/reproductivehealth/publications/maternal_perinatal_health/9241590947/en/.

8. Ngxongo TSP, Sibiya MN. Factors influencing successful implementation of the basic antenatal care approach in primary health care facilities in eThekwini district, KwaZulu-Natal. Curationis. 2013;36(1):1-7.

9. 10.4102/phcfm.v10i1.1300

Kaswa R, Rupesinghe GFD, Longo-Mbenza B. Exploring the pregnant women's perspective of late booking of antenatal care services at Mbekweni Health Centre in Eastern Cape, South Africa. Afr J Prim Health Care Fam Med. 2018;10(1):e1-e9. Published 2018 Jul 2. D0l:10.4102/phcfm.v10i1.1300.

10. Zegeye AM, Bitew BD, Koye DN. Prevalence and determinants of early antenatal care visit among pregnant women attending antenatal care in Debre Berhan Health Institutions, Central Ethiopia. Afr J Reprod Health. 2013;17(4):130-6.

11. Mengesha Geta WW. Early Initiation of Antenatal Care and Factors Associated with Early Antenatal Care Initiation at Health Facilities in Southern Ethiopia. Advances in Public Health. 2017.

12. Aung TZOW, Khaing W, Lwin N, Dar HT. Late initiation of antenatal care and its determinants: a hospitalbased cross-sectional study. Int J Community Med Public Health. 2016.

13. Florde María, Cáceres-Manrique, Myriam RR. Prevalence of late initiation of prenatal care. Association with the socioeconomic level of the pregnant woman. Revista Colombiana de Obstetrician y Ginecología Bucaramanga, Colombia,2014-2015;69(1).

14. World Health Organization, UNICEF, United Nations Population Fund, World Bank. Trends in Maternal Mortality: 1990 to 2008: Estimates. World Health Organization; 2010. 
15. Dutta DC. Text Book of Obstetrics. 7th Ed. Calcutta, India: Jaypee Brothers Medical Publishers (P) Ltd. Chapter 38: Special Topics in Obstetrics; 2013;631.

16. Zegeye AM, Bitew BD, Koye DN. Prevalence and determinants of early antenatal care visit among pregnant women attending antenatal care in Debre Berhan Health Institutions, Central Ethiopia. Afr J Reprod Health. 2013;17(4):130-6.

17. Central Statistical Agency [Ethiopia]. Ethiopia Demographic and Health Survey. Addis Ababa, Ethiopia, and Calverton, Maryland, USA: Central statistical agency. ICF international. 2014.

18. Banda I, Michelo C, Hazemba A. Factors associated with late antenatal care attendance in selected rural and urban communities of the Copperbelt province of Zambia. Medical Journal of Zambia. 2012;39(3):29-36. DOI:10.4314/mjz.v39i3.

19. Magoma M, Requejo J, Campbell OM, Cousens S, Filippi V. High ANC coverage and low skilled attendance in a rural Tanzanian district: a case for implementing a birth plan intervention. BMC Pregnancy Childbirth. 2010;10(1):13. DOI:10.1186/1471-2393-10-13.

20. Tekelab T. and BB. Factors Associated with Late Initiation of Antenatal Care among Pregnant Women Attending Antenatal Clinic at Public Health Centers in Kembata-Tembaro Zone, Southern Ethiopia. Arts Res J Jan-April. 2014;3(2):108-15.

21. Worku TMS, Amano A. Timing and factors associated with first antenatal care booking among pregnant mothers in Gondar Town; North West Ethiopia. BMC Res Notes. 2014;19[2]:93-9.

22. Gulema H, Berhane Y. Timing of First Antenatal Care Visit and its Associated Factors among Pregnant Women Attending Public Health Facilities in Addis Ababa, Ethiopia. Ethiop J Health Sci. 2017;27(2):139-46. DOI:10.4314/ejhs.v27i2.6.

23. Ethiopia - Demographic and Health Survey. 2016. Accessed August 15, 2020. https://microdata.worldbank.org/index.php/catalog/2886.

24. Paudel YR, Jha T, Mehata S. Timing of First Antenatal Care (ANC) and Inequalities in Early Initiation of ANC in Nepal. Frontiers in Public Health. 2017;5. DOI:10.3389/fpubh.2017.00242.

\section{Figures}




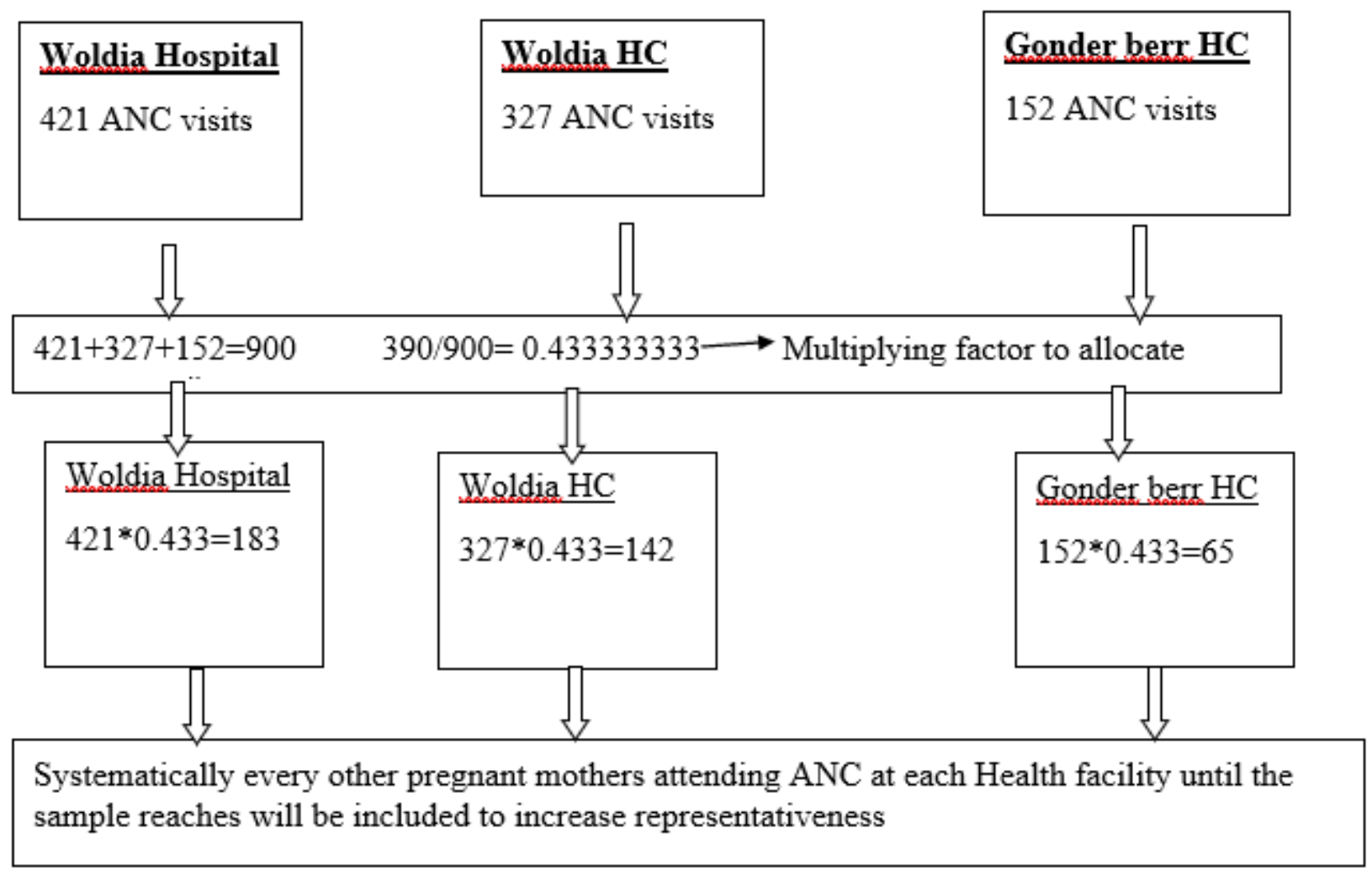

\section{Figure 1}

sampling procedures to assess the magnitude and factors associated with ANC among pregnant mothers attending ANC at public health institutions of Woldia town, 2019.

\section{Supplementary Files}

This is a list of supplementary files associated with this preprint. Click to download.

- Questionarries.docx 